\title{
Design and construction of a trap for the surveillance of Aedes (Stegomyia) aegypti (Diptera: Culicidae)
}

\author{
Diseño y construcción de una trampa para el monitoreo \\ de Aedes (Stegomyia) aegypti (Diptera: Culicidae)
}

Jessica Peña Torres ${ }^{1}$, Mónica Navarro Aranda ${ }^{1}$, Héctor Julio Parra Moreno ${ }^{1}$, Jonny Edward Duque Luna ${ }^{1}$

Suggested citation: Peña Torres J, Navarro Aranda M, Parra Moreno J, Duque Luna JE. Design and construction of a trap for the surveillance of Aedes (Stegomyia) aegypti (Diptera: Culicidae). Rev Univ Ind Santander Salud. 2016; 48(3): $285-294$. DOI: http://dx.doi.org/10.18273/revsal.v48n3-2016002 @) (1) Ð

\begin{abstract}
Introduction: Understanding Aedes (Stegomyia) aegypti (L) behavior will provide insight into the design of entomological surveillance devices. Objective: Design and build a trap for surveillance Aedes aegypti. Methodology: We examined egg-laying preference and the ability to capture adult Ae. aegypti using containers that differed in shape, color and internal retention systems. The characteristics most effective in capturing adult mosquitoes were used to develop a prototype efficient in trapping mosquitoes. The shape of the prototype was determined by examining oviposition preference of containers having circular, square and triangular bases. Color discrimination was assessed by covering the bodies of the containers in green $(523 \mathrm{~nm})$, red $(621 \mathrm{~nm})$, white and gray (the chromatic scale from black to white). The propensity of Ae. aegypti to enter the containers was assessed by incorporating an entrance to the container in the shape of an inverted truncated oblique pyramid with base, middle and apex dimensions of $6.5-4 \mathrm{~cm}, 5-2.5 \mathrm{~cm}$ and $4.5-1.5 \mathrm{~cm}$, respectively. All variables as the number of egg and adults captured in treatments were subjected to variance analysis; only data with $\mathrm{P}<0.05$ were considered significant. Results: Our results indicate that neither shape nor entrance dimension attract ovipositing $A e$. aegypti females $[\mathrm{K}-\mathrm{W}: \mathrm{H}(3, \mathrm{~N}=64)=0.3222769 \mathrm{p}=0.9558$ and $\mathrm{K}-\mathrm{W}: \mathrm{H}(3, \mathrm{~N}=16)=4.284865 \mathrm{p}=0.2323$, respectively]. However, we found that the color red had a high positive response [K-W: $\mathrm{H}(4, \mathrm{~N}=80)=20.81260 \mathrm{p}$ $=0.0003]$. Conclusions: The final design of the trap resembled a truncated pyramid with a red square base, a black oblique entrance of $5 \times 2.5 \mathrm{~cm}$ and an internal retention system. The final prototype had a capture rate of $90.5 \pm 5 \%$ under laboratory conditions.
\end{abstract}

Keywords: Oviposition, design, disease vectors, behavior, insect control.

1. Universidad Industrial de Santander. Bucaramanga, Colombia

Correspondence: Jonny Edward Duque Luna. Address: Facultad de Salud UIS, Carrera 32 29-31, Bucaramanga, Santander, Colombia. Email: jonedulu@uis.edu.co. Phone number:+7 6344000 Ext. 3159 


\section{RESUMEN}

Introducción: Aspectos etológicos de Aedes (Stegomyia) aegypti (L) proporcionan el conocimiento para diseñar dispositivos para la vigilancia entomológica. Objetivo: Diseñar y construir una trampa para el monitoreo de Aedes aegypti. Metodología: Experimentos de ovipostura y captura de alados de Ae. aegypti fueron realizados con contenedores diseñados de acuerdo a forma, color y sistemas internos de retención. Las contenedores con mayor eficiencia de ovipostura y captura de adultos fueron usados para diseñar el prototipo de la trampa. La forma del dispositivo se determinó por medio de la preferencia de ovoposición con prototipos de base circular, cuadrada y triangular. La discriminación por el color, se evaluó cubriendo los contenedores de color verde $(523 \mathrm{~nm})$, rojo (621 $\mathrm{nm}$ ), blanco y gris (que pertenecen a la escala cromática que va del negro al blanco), todos con una abertura de entrada de color negro. La capacidad de ingreso de Ae. aegypti a los contenedores fue evaluada incorporando una entrada al contenedor en forma de pirámide oblicua truncada invertida con dimensiones en la base, área media y ápice de 6,5-4 cm, 5-2,5 cm y 4,5-1,5 cm respectivamente. Todos los experimentos fueron sometidos a análisis de variancia con el programa "Statistica v11", únicamente datos con $\mathrm{p}<0.05$ se consideraron significativos. Resultados: Los resultados indicaron que la forma no influencia la atracción de ovoposición de las hembras de Ae. aegypti [K-W: H $(3, \mathrm{~N}=64)=0.3222769 \mathrm{p}=0.9558]$ y el color rojo presenta alta selección $(\mathrm{K}-\mathrm{W}: \mathrm{H}(4, \mathrm{~N}=80)=20.81260 \mathrm{p}=$ $0.0003)$. Las dimensiones de la entrada no tienen significancia en la captura de los mosquitos[K-W: $\mathrm{H}(3, \mathrm{~N}=16)=$ $4.284865 \mathrm{p}=0.2323]$. Conclusión: El diseño final de la trampa tuvo forma de pirámide truncada de base cuadrada de color rojo, con entrada oblicua negra de dimensiones de entrada 5 x 2,5 cm más un sistema interno de retención. El prototipo final presentó $90.5 \pm 5 \%$ de captura en los experimentos de laboratorio.

Palabras clave: Ovoposición, diseño, vectores de enfermedades, comportamiento, control de insectos.

\section{INTRODUCTION}

The control of insects that transmit human disease requires appropriate devices for entomological surveillance. In monitoring diseases such as Dengue, Chikungunya and Zika, several tools have been created to potentiate the active and passive search for Aedes aegypti ${ }^{1-4}$. Depending on the life stage of the mosquito, surveillance measures such as ovitraps, larvitraps, pupae and adults collection have been used to assess the presence and density of mosquito populations. While the above methods provide information on the number of eggs, larvae and pupae in the areas where they are deployed, they are unable to accurately estimate genuine densities of local mosquito populations ${ }^{5}$.

Monitoring of Ae. aegypti adults is a more attractive option than monitoring immature life stages, as it more accurately assesses the actual density of the mosquito population. Therefore, new vectorsurveillance tools have been designed to capture adult mosquitoes. These include various vacuums and traps that electromechanically collect insects, such as: BG-Sentinel ${ }^{\mathrm{TM}}$, Fay-Prince trap, MosquiTRAPT, stickyovitrap, Adultrap, and Sticky Trap ${ }^{3,4,6,7}$.

Traps that collect adult mosquitoes have many advantages, including their ability to provide material for physiological, morphometric and genetic analyses as well as to allow for the determination of gonadotropic status and host blood sources. Such information is important to understand mosquito population dynamics and to establish strategies for disease control based on the vector population ${ }^{8-10}$. An additional benefit of adult mosquito collection is that it allows for viral analysis in the areas of collection ${ }^{11}$.

Despite our extensive knowledge of the biology and ecology of Ae. aegypti, there is currently no standard model regarding the methodology for designing devices that efficiently capture adult mosquitoes. Ae. aegypti behavioral responses to visual, chemical and tactile stimuli in selecting oviposition sites have been studied $^{12}$. However, these stimuli are only detected from relatively short distances. Further, mosquitoes in flight respond to such stimuli visually ${ }^{13,14}$. Thus, the design of mosquito traps should account for aspects such as shape and color in order to maximize capture.

Aedes aegypti selects various water-holding objects for oviposition. These objects include containers, tires, bottles, bottle caps, etc. ${ }^{15}$. While gravid Ae. aegypti females utilize a wide array of containers for egg-laying, they have a documented preference for dark places and surfaces ${ }^{16}$. The dark surface preference for oviposition is a pattern that involves black-white contrast ${ }^{16-19}$. Moreover, female Ae. aegypti can discriminate within the color spectra between ultraviolet $323 \mathrm{~nm}$ and red 
$621 \mathrm{~nm}$, with peaks in ultraviolet 323-345 nm and green $523 \mathrm{~nm}^{20}$.

This study aims to contribute to the design of devices that will capture gravid female Ae. aegypti using oviposition site selection behavior as a guideline.

\section{MATERIALS AND METHODS}

Biological material. Experiments were conducted with Ae. aegypti, Rockefeller strain, maintained in $40 \times 40$ $\times 40 \mathrm{~cm}$ cages in an insectary at $25 \pm 5^{\circ} \mathrm{C}, 70 \pm 5 \%$ humidity and a 12:12 photoperiod. Female mosquitoes were continuously offered a $10 \%$ honey solution $(75 \%$ carbohydrates). When eggs were needed to obtain adults, females were fed by inserting the forearm of a researcher into the cage for 15 minutes (authorized by the ethics committee). Once females were fed, they were held in the same cage and allowed to lay their eggs on filter paper in a glass containing $50 \mathrm{~mL}$ of mineral water.

Adult mosquitoes used for trap design experiments. Four days after blood feeding, the filter paper with the laid eggs was removed, labeled and left to dry for three days under the same conditions. Eggs were stimulated to hatch in plastic trays $(35.5 \mathrm{~cm} \times 21.5 \mathrm{~cm} \times 6.5 \mathrm{~cm})$ with ca. $3,000 \mathrm{~mL}$ of dechlorinated water with $1 \mathrm{~g}$ of TetraminTM fish concentrate. Pupated larvae were transported to holding cages where adults emerged for use in experiments.

Experiments on visual attraction. Tests were conducted to determine whether Ae. aegypti females had an oviposition preference based on the shape and color of the oviposition container. Response to container shape: To determine whether shape influenced oviposition, cardboard containers measuring $13 \times 13 \times 20 \mathrm{~cm}$ were constructed that had a circular, square or triangular shape. A hole was made in each, which served as the container entrance (Figure 1A).

A container filled with $30 \mathrm{~mL}$ of dechlorinate water and lined with filter paper (the oviposition substrate) was placed into each trap. Larvae about to reach the pupal stage were taken from the breeding colony and isolated in a breeding cage until they completed their life cycle. Approximately two hundred individuals at a sex ratio of 1:1 were used. The resulting adults were fed with the sugar solution and allowed to mate. Mated females were subsequently blood-fed for 15 to 20 minutes, rested for $\sim 24$ hours, and then separated and transported to the test cages. A total of eighty gravid females of the same physiological age and a maximum of five days after pupating were placed in four cages of $70 \times 70 \times 70 \mathrm{~cm}$ for the experiments; each cage served as a replicate (four replicates) with twenty females and three experimental containers (circular, square and triangular) distributed at equal distances from each other $(20 \mathrm{~cm})$. A colorless glass container filled with $30 \mathrm{~mL}$ of distilled water and lined with filter paper served as a control and was placed in the center of each cage. A bowl covered with filter paper and containing sugar water was placed in the lower right-hand corner to prevent mortality due to the absence of feeding. Each experiment was conducted for seven days. Control and experimental containers were replaced every 24 hours. When containers were replaced, they were rotated counterclockwise to avoid selection bias ${ }^{19}$. Eggs laid on the collected filter paper were counted daily using a stereoscopic magnifier (Olympus S2X9). To determine whether the control treatment affected oviposition behavior, a second experiment was carried out simultaneously (under the same conditions) without the control container.

Response to container color: Based on the results of the shape experiment, we developed a test to asses whether female Ae. aegypti were able to select an oviposition site in accordance with the color of the container. Cardboard containers of $13 \times 13 \times 20 \mathrm{~cm}$ were built with a $3 \times 3 \mathrm{~cm}$ hole at the top and a black cardboard edge ${ }^{17,18}$ (Figure 1B). Four colors were selected to cover the body of the container: green equivalent to $523 \mathrm{~nm}$, red equivalent to $621 \mathrm{~nm}^{20,21}$, white [of the documented black-white combination ${ }^{16,19}$ ] and gray (similar to the black-white but with a reduction in the intensity of white). The control treatment was a container covered in imitation grass paper. The experimental cages were also lined with imitation grass paper from the bottom half to the base (Figura1B). A total of eighty females were used: twenty females per cage, four replicates. Each experiment was conducted for seven days. The number of eggs laid in each treatment was determined as described in the previous section.

Entrance design and the mosquito retention system of the containers. Based on the results of the shape and color experiments, we attempted to build an entrance to the trap according to female Ae. aegypti behavioral preferences. Trap entrance: It was suggested to us that mosquito access to the container should be in the shape of an inverted, truncated pyramid to facilitate mosquito entry and prevent their escape. Three variations of the trap entrance were assessed for their ability to capture mosquitoes. Entrance 1: external measurement $6.5 \mathrm{~cm}$, internal measurement $4 \mathrm{~cm}$, height $5 \mathrm{~cm}$. Entrance 2: external measurement $5 \mathrm{~cm}$, internal measurement 2.5 
$\mathrm{cm}$, height $5 \mathrm{~cm}$. Entrance 3: external measurement $4.5 \mathrm{~cm}$, internal measurement $1.5 \mathrm{~cm}$, height $4 \mathrm{~cm}$ (Figure 1C). Containers were built with translucent cellulose acetate and measured 13 × 13 × $20 \mathrm{~cm}$. Except for the entrances, which were black, the containers were covered with red paper based on the results of the color experiment. A total of sixteen containers were used, distributed in three treatments (entrance dimensions) plus one control per cage; four replicate experiments were conducted. 160 females in the same physiological conditions as the previous experiments were used; females were distributed in groups of four per cage. Oviposition glasses were covered with a fine net to prevent females from laying eggs. The control treatment was a $13 \times 13 \times 20 \mathrm{~cm}$ container with a flat $3 \times 3 \mathrm{~cm}$ entrance (the same entrance used in the color experiment). We counted the number of mosquitoes captured in each treatment after $168 \mathrm{~h}$.

Retention mechanisms. After determining the dimensions of the entrance, two prototypes were assessed for their ability to retain mosquitoes within the trap.

Description of the first prototype (A). Prototype A consisted of a red parallelepiped structure with two sides opposite the mosquito net fabric. A black cardboard wall with vertical slots divided the container in two. This was set up parallel to the black net. The purpose of the slots was to allow the passage of light and air stimuli and to allow the mosquitoes to move from one side of the wall to the other. The structure also had a lower compartment where the oviposition substrate was placed (covered with a net barrier). An entrance in the shape of an oblique truncated pyramid was placed at the top of the trap; the oblique slope blocked the entry of light from outside (Figure 2A)

Description of the second prototype (B). Prototype B consisted of a red parallelepiped container made of three compartments: upper, middle and lower. The entrance of the trap was located in the upper compartment (on the edge between the top and front side) and resembled an oblique truncated pyramid. The upper and middle compartments were connected through a triangular hole. The middle compartment had two sides opposite the net fabric and a black internal wall with slots to allow the passage of light and air stimuli and to allow mosquito movement from one side of the wall to the other. The lower compartment contained the oviposition substrate covered with a cloth barrier (Figure 2B).

The two experimental models were manufactured in cardboard and covered with red paper. The translucent cellulose acetate surface allowed for the flow of light and air through the mosquito net. The entrance mechanism of the containers was black. The prototype traps were assessed together in a cage along with a control treatment (of the same characteristics as the color experiment). 160 females were used with a distribution of 40 per cage, for a total of four replicates. The experiment was carried out for seven days. Mosquito capture was assessed twice, on day two and day four, to determine whether the mosquitoes were escaping from the traps.

Prototype $B$ mosquito escape rate. Using the most effective prototype in capturing mosquitoes, prototype $\mathrm{B}$, we assessed whether mosquitoes were escaping from inside the trap. A total of twenty gravid females were inserted directly into prototype B and the control trap, under the same conditions as the previously described experiments. Mosquitoes were counted after four days to determine the number of mosquitoes remaining in each trap. Two treatments were assessed: prototype $\mathrm{B}$ and the control trap (the same as the previous experiment). The test was replicated four times using a total of 160 mosquitoes.

Construction of the final prototype. Based on the results of the capture experiments of prototypes A and B and the escape test for prototype $\mathrm{B}$, a final design of the trap was made ("prototype C"; Figure 2C). At this stage, the trap was defined as a product in terms of interface, materials, the production process, the number of parts and their sequence of use ${ }^{22}$. Using this methodology, a trap was built from polymethly methacrylate with a red latex coating that had the consensus dimensions of the experimental results and that implemented industrial design methodology (Figure 3). A final test was conducted of the consensus prototype to determine female capture rate. Prototype $\mathrm{C}$ was inserted into a cage along with a control treatment (a $13 \times 13 \times 20 \mathrm{~cm}$ container with a flat $3 \times 3 \mathrm{~cm}$ entrance). 200 females were used for this experiment. After 4 days, the number of females captured was counted.

Escape test of the final prototype. Determination of the number of mosquitoes escaping from the prototype $\mathrm{C}$ was based on the escape experiment of prototype B.

Statistical analysis. Were used the KolmogorovSmirnov test for normality indicated that the data (experiments) are no-normal distribution. The results were analyzed using test non-parametric KruskallWallis (KW), only $\mathrm{P}<0.05$ were considered significant and multiple-comparisons tests were used when data were significantly different, the software uses in all analyses was. Statistica v11. 


\section{RESULTS}

Visual attraction to the shape of the container. All treatments were positive in terms of the presence of laid eggs. Although we detected no significant differences $[K-W: \mathrm{H}(3, \mathrm{~N}=64)=0.3222769 \mathrm{p}=0.9558]$ (Figure $1 \mathrm{~A})$, the control treatment had the highest number of eggs while the triangular container had the fewest (Table 1). In experiments where the control treatment was not included, the square container had the highest number of eggs, although no significant differences were found $[\mathrm{K}-\mathrm{W}: \mathrm{H}(2, \mathrm{~N}=48)=0.2650122 \mathrm{p}=$ 0.8759], (Table 1). These results show that container shape does not influence oviposition site selection of gravid Ae. aegypti females.

Table 1. The number of eggs laid (mean \pm S.E.) after sevendays by Ae. aegypti females in containers of the specified shape.

\begin{tabular}{lcc}
\hline \multirow{2}{*}{$\begin{array}{c}\text { Container } \\
\text { Shape }\end{array}$} & \multicolumn{2}{c}{ Number of eggs (Mean) } \\
& With controla & Without controla $^{2}$ \\
\cline { 2 - 3 } Circular & $406 \pm 34.93$ & $735 \pm 236.21$ \\
& $(25.37)^{\mathrm{a}}$ & $(45.93) \mathrm{a}$ \\
Square & $406 \pm 29.54$ & $975 \pm 170.98$ \\
& $(25.37) \mathrm{a}$ & $(60.93) \mathrm{a}$ \\
Triangular & $366 \pm 39.10$ & $908 \pm 213.70$ \\
& $(25.37) \mathrm{a}$ & $(56.75) \mathrm{a}$ \\
Control & $501 \pm 38.02 \mathrm{a}$ & \\
& $(22.87)$ & N.A $^{1}$ \\
\hline
\end{tabular}

${ }^{1}$ No control treatment was used

${ }^{2}$ Means in the same row and/or column marked with the same letter indicate that there were no significant statistical differences $(\mu=0.05)$.

Response to color. The red-black containers were selected significantly more often for oviposition compared to the other containers $[\mathrm{K}-\mathrm{W}: \mathrm{H}(4, \mathrm{~N}=80)=20.81260 \mathrm{p}=$ 0.0003] (Table 2). The green-black containers were the least attractive for the females to lay their eggs. These results indicate that the red-black contrast influences oviposition site selection of Ae. aegypti females (Figure 1B).

Assessment of entrance dimension and the mosquito retention ability of the containers. The entrances of maximum and minimum dimensions were least effective in capturing females than the entrances of intermediate dimensions (Table 3). However, no significant differences between the treatments were observed [K-W: $\mathrm{H}(3, \mathrm{~N}=16)=4.284865 \mathrm{p}=0.2323]$. The entrance that captured the most mosquitoes was taken as a reference for the final design of the prototype trap: $5 \times 5 \mathrm{~cm}$ outer diameter and $2.5 \times 2.5 \mathrm{~cm}$ inner diameter (Figure 1C).
Table 2. The number of eggs laid (mean \pm S.E.) after 7-days by Ae. aegypti females in containers of the specified color.

\begin{tabular}{lc}
\hline Color & $\begin{array}{c}\text { Number of eggs } \\
\text { (Mean) }\end{array}$ \\
\hline White & $56 \pm 26.68$ \\
& $(3.5)^{\mathrm{a}}$ \\
Grey & $108 \pm 22.49$ \\
& $(6.75)^{\mathrm{a}}$ \\
Red & $594 \pm 31.37$ \\
& $(37.12)^{\mathrm{b}}$ \\
Green & $19 \pm 9.5$ \\
& $(1.18)^{\mathrm{a}}$ \\
Control & $22 \pm 7.14$ \\
& $(1.37)^{\mathrm{a}}$ \\
\hline
\end{tabular}

${ }^{1}$ Means in the same column marked with the same letter indicate that there were no significant statistical differences $(\mu=0.05)$.

Table 3. The number (mean \pm S.E.) of gravid female $A e$. aegypti captured in containers having the specified entrance dimensions during the 6-day observation period.

\begin{tabular}{cc}
\hline $\begin{array}{c}\text { Entrance dimensions, } \\
\text { outer, inner measurements } \\
\text { and height in cm }\end{array}$ & $\begin{array}{c}\text { Number of female } \\
\text { mosquitoes captured } \\
\text { ( Mean) }\end{array}$ \\
\hline 6.5 x 5 × 5 & $5 \pm 1.15$ \\
& $(1.66)^{\mathrm{a}}$ \\
$5 \times 2.5$ x 5 & $8 \pm 1.52$ \\
& $(2.66)^{\mathrm{a}}$ \\
4.5 x 1.5 × 4 cm & $5 \pm 0.5$ \\
& $(1.66)^{\mathrm{a}}$ \\
Control & $6 \pm 0.0$ \\
$3 \times 3^{*}$ & $(2)^{\mathrm{a}}$ \\
\hline
\end{tabular}

${ }^{1}$ Means in the same column marked with the same letter indicate that there were no significant statistical differences $(\mu=0.05)$.

* The control does not have an entrance in the shape of a truncated pyramid; the entrance is flat.

Retention mechanism and mosquito escape rate from prototypes. Prototype A was less efficient than prototype B at capturing mosquitoes (Table 4). Capture of Ae. aegypti females by prototype $\mathrm{B}$ were significantly more effective on day two [K-W: H (2, $\mathrm{N}=12)=9.202679 \mathrm{p}=0.0100]$ and day four $[\mathrm{K}-\mathrm{W}$ : $\mathrm{H}(2, \mathrm{~N}=12)=6.929211 \mathrm{p}=0.0313$ ] (Figure 2A, B; Table 4). Further, all 20 females introduced into prototype B during our experiments remained inside the trap after four days. For comparison, the control trap had a $78 \%$ escape rate. Based on these results, prototype B was selected as the reference for the final trap design. However, we made additional adjustments (described below) to the design in order to capture more mosquitoes. 

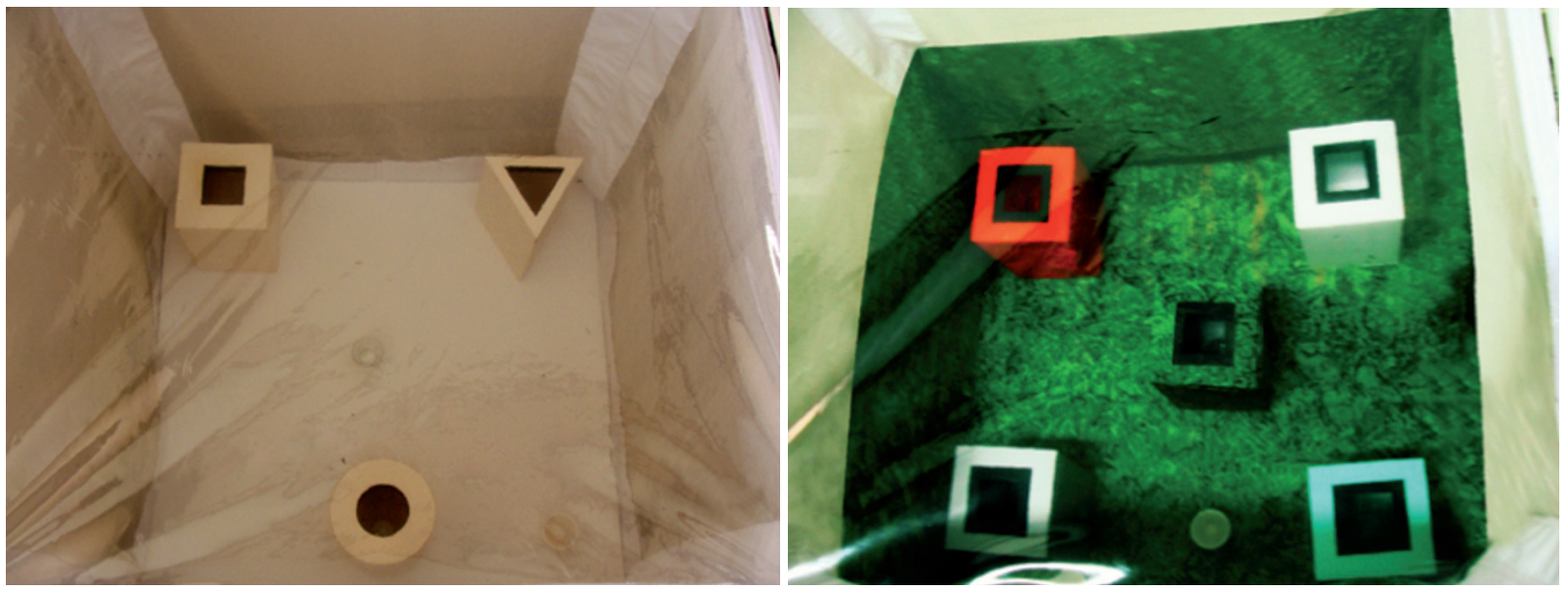

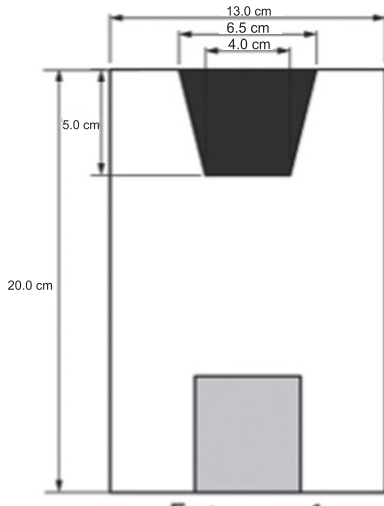

Entrance 1

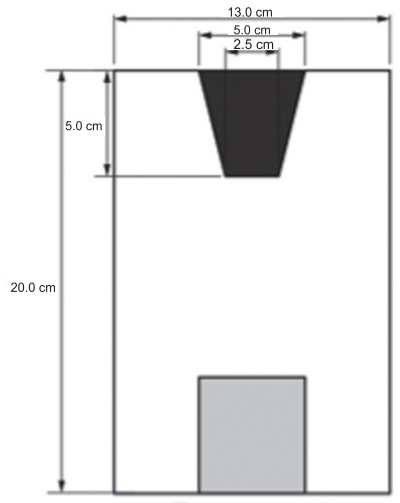

Entrance 2

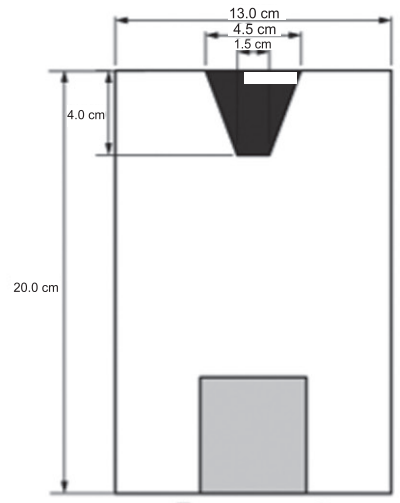

Entrance 3

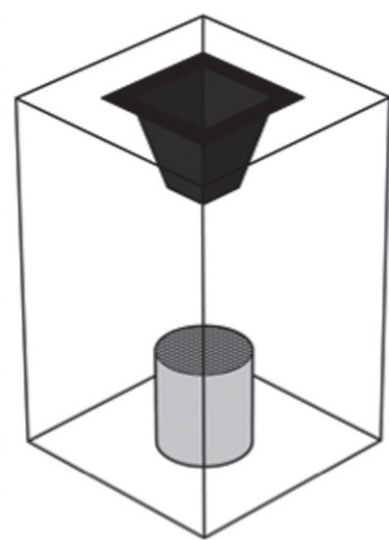

Figure 1. (A) Experimental setup to determine the response to trap shape. (B) Experimental setup to determine the response to trap color. (C) Entrance dimensions of the experimental models.

Table 4. The number (mean \pm S.E.) of gravid female $A e$ aegypti captured by prototype traps A and B during the 5-day observation period.

\begin{tabular}{lcc}
\hline $\begin{array}{c}\text { Retention } \\
\text { mechanism }\end{array}$ & $\begin{array}{c}\text { Initial count } \\
\text { (day 2) ( Mean) }\end{array}$ & $\begin{array}{c}\text { Final count } \\
\text { (day 4) (Mean) }\end{array}$ \\
\hline \multirow{2}{*}{ Prototype A } & $17 \pm 1.5$ & $21 \pm 1.7$ \\
& $(4.25)^{\mathrm{a}}$ & $(5.25)^{\mathrm{a}}$ \\
Prototype B & $38 \pm 3.69$ & $33 \pm 2.06$ \\
& $(9.5)^{\mathrm{b}}$ & $(8.5)^{\mathrm{ab}}$ \\
Control & $1 \pm 0.5$ & $10 \pm 2.38$ \\
& $(0.25)^{\mathrm{a}}$ & $(2.5)^{\mathrm{b}}$ \\
\hline
\end{tabular}

${ }^{1}$ Means in the same column marked with the same letter indicate that there were no significant statistical differences $(\mu=0.05)$.

Adjustment to the retention mechanism. We modified the trap entrance, increasing its width and curving the internal entrance channel (Figure 2C) in order to block the entry of light from outside the trap. While we observed no significant difference between the results using this modified entrance and the one used previously [K-W: $\mathrm{H}(2, \mathrm{~N}=12)=$ $3.566254 \mathrm{p}=0.1681$ ], the capture rate of the trap with these changes was increased (Table 5). These results and those of the previous experiments established mosquito attraction, entry and retention within the trap, each of which were considered for the final design of the product.

Table 5. The number (mean \pm S.E.) of gravid female $A e$. aegypti captured in traps using the modified entrance dimensions during the four-day observation period.

\begin{tabular}{cc}
\hline $\begin{array}{c}\text { Prototype B } \\
\text { (entrance dimension) }\end{array}$ & $\begin{array}{c}\text { Captured } \\
\text { (Mean) }^{\mathbf{1}}\end{array}$ \\
\hline $5 \mathrm{~cm}$ & $17 \pm 2.62$ \\
& $(4.25)^{\mathrm{a}}$ \\
$7 \mathrm{~cm}$ & $32 \pm 2.44$ \\
& $(8)^{\mathrm{b}}$ \\
Control & $16 \pm 4.24$ \\
& $(4)^{\mathrm{a}}$ \\
\hline
\end{tabular}

${ }^{1}$ Means in the same column marked with the same letter indicate that there were no significant statistical differences $(\mu=0.05)$. 
Description of the final prototype. The final prototype, prototype $\mathrm{C}$, has the same structural characteristics as prototype B, utilizing a black entrance in the same location but with the entrance modifications described above (Figure 2C). The functional performance of the final prototype (Figure
3A, B), built with manufacturing materials, was exceptional: prototype $\mathrm{C}$ captured 181 females $(90.5$ $\%)$ of the total mosquitoes in the test cage compared to only $4(2.2 \%)$ for the control. The escape rate of prototype C was $0 \%$. We refer to this prototype as StegTrap.
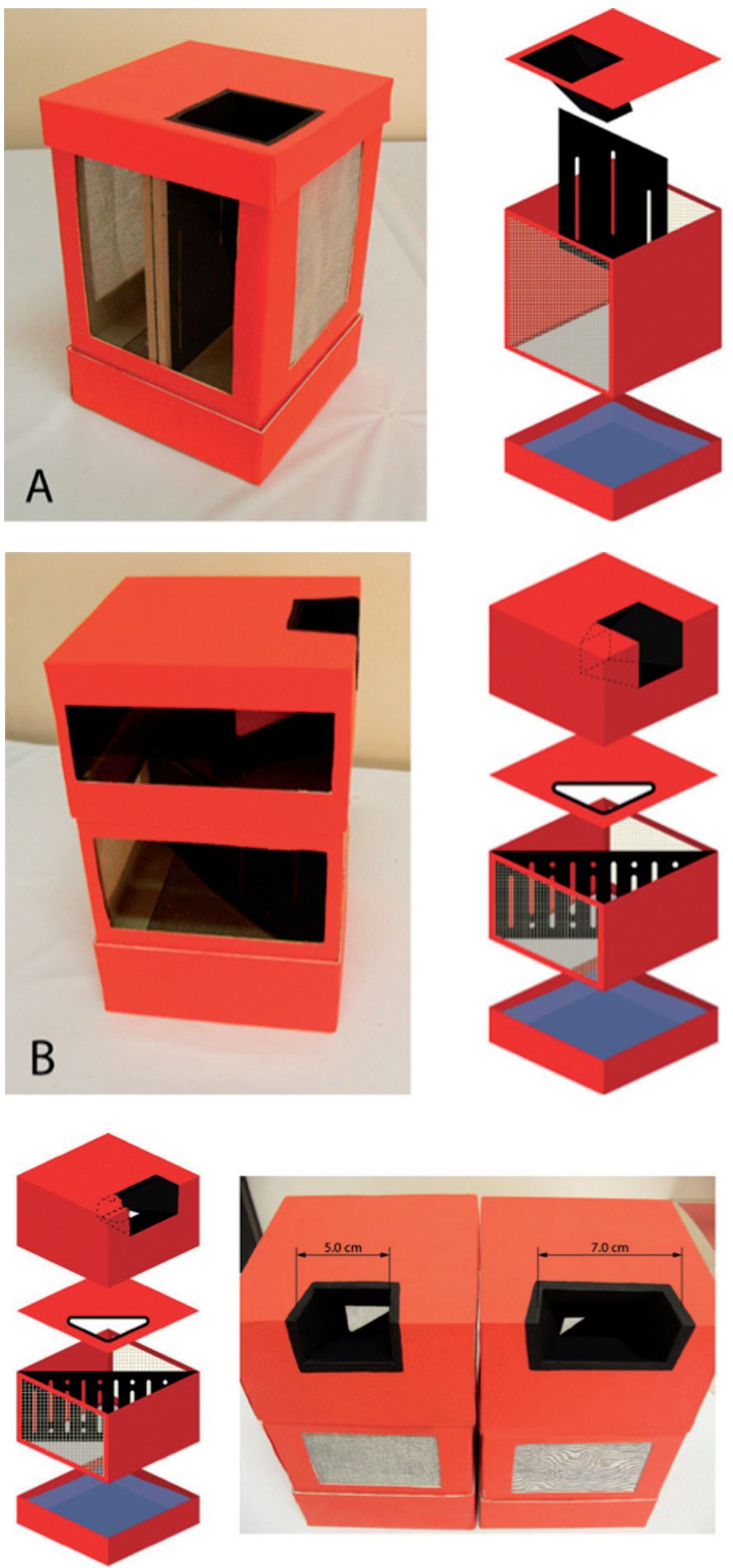

Figure 2. (A) Prototype trap A. (B) Prototype trap B. (C) Experimental models entrance mechanisms 

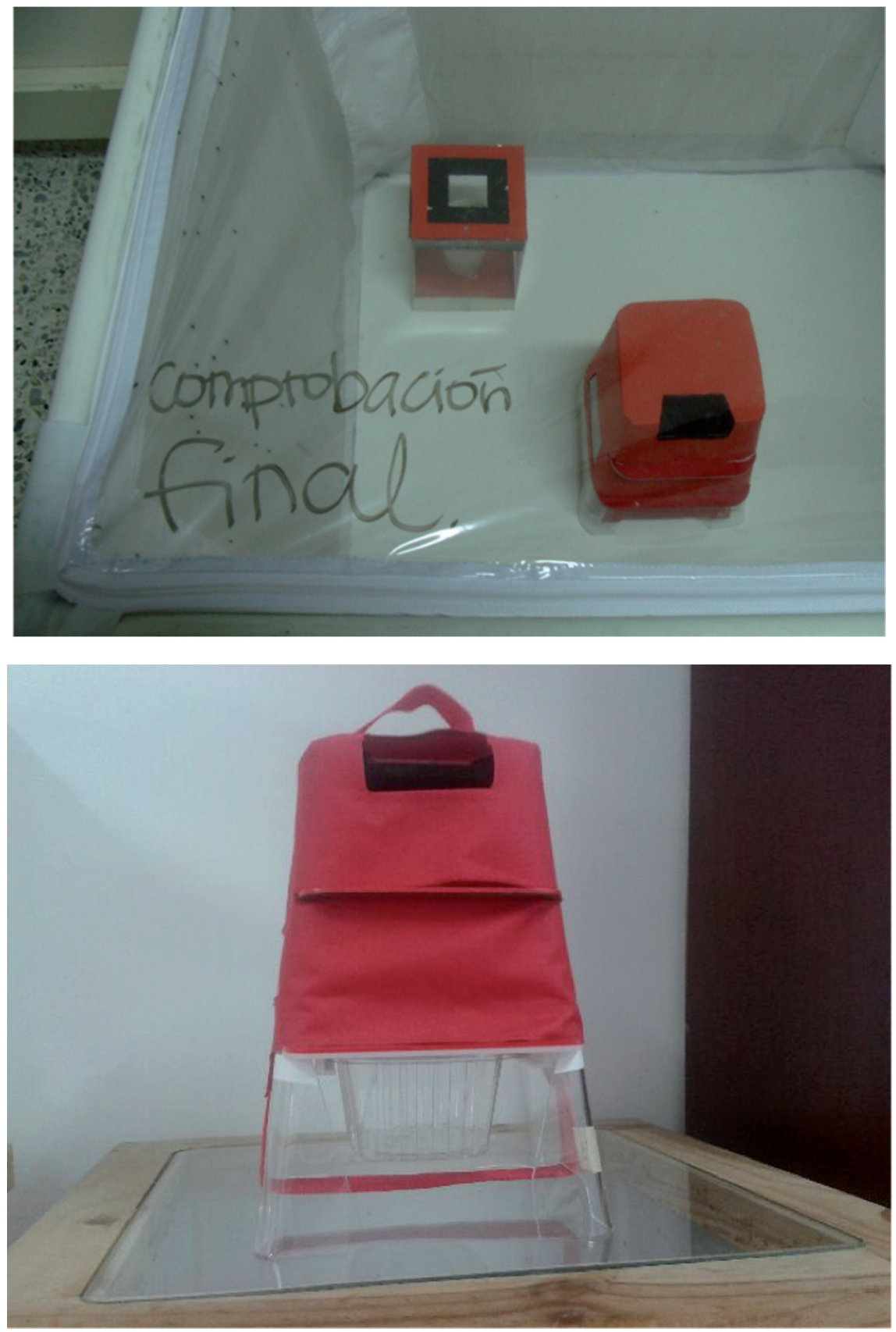

Figure 3. Final Ae. aegypti capture test (A) and final prototype of the trap (StegTrap) (B).ure

\section{DISCUSSION}

The design and development of monitoring tools such as mosquito traps requires an understanding of how individuals behave when faced with the options provided by their surroundings. The behavior of $A e$. aegypti females in selecting suitable oviposition sites depends on the presence of a water source ${ }^{15,23}$. Based on this premise, building devices to capture this species can be highly effective provided they are designed with the objective of providing the mosquito with suitable oviposition substrates.

The results reported here are consistent with previous studies that examined oviposition behavior of Ae. aegypti females. Culicidae females will oviposit in a wide variety of containers -cans, tires, caps, bottle and other types of containers ${ }^{15}$ - results confirmed by the trap models assessed in this study. Aedes aegypti females look for places where their eggs can survive 
Design and Construction of a Trap for the surveillance of Aedes (Stegomyia) aegypti (Diptera: Culicidae)

due to the presence of semiochemicals in the water and not because of the shape of the container ${ }^{23}$. Therefore, the volumetric shape of traps can focus on aesthetic requirements (unit, harmony, finishes), functionality (storage and transport), usability (monitoring and cleaning) and production costs (production processes and materials). These characteristics ensure the production and marketing of traps will contribute to addressing public health problems ${ }^{22}$.

Responses to visual, chemical and tactile stimuli have been widely studied in Ae. aegypti females ${ }^{12,20,21}$. Color preference of Ae. aegypti females are primarily based on a greater attraction to dark surfaces ${ }^{16}$. Black surfaces have been found to be most attractive in oviposition site selection ${ }^{17,18}$. Other studies have documented the attraction to a black-white contrast ${ }^{16,19}$. However, Muir, et al. ${ }^{20}$ suggested that Ae. aegypti and Ae. albopictus (Skuse) females ${ }^{24,25}$ prefer red and black breeding areas, while colors such as blue, yellow and white are unattractive to them. These findings are consistent with the results of the current study.

We report here that a red-black contrast present at the entrance of the trap results in higher mosquito capture than the other colors examined. Although it was evident that females preferred this contrast, no current trap uses this characteristic in their design. For example, traps on the market for capturing Ae. aegypti such as the BGSentinel ${ }^{\mathrm{TM}}$ and the Fay-Prince trap contrast a black entrance with the white body while MosquiTRAPTM, Sticky Ovitrap and Adultrap are completely black ${ }^{3,67}$. Therefore, the trap presented here may be the first to use the red-black combination suggested as optimal based on the natural behavior of Ae. aegypti females in selecting an oviposition container. A trap that provides the preferred visual stimulation in the mosquitoes' natural environment will undoubtedly increase its capturing capacity.

Regarding the proposed entrance mechanism, our prototype differs from the traps mentioned above. The entrance of our trap takes the shape of an inverted truncated pyramid with a square base. This ensures that no light enters the trap, which can disorient the captured mosquitoes ${ }^{14}$. In order to have a wide entrance like traps currently on the market, we modified the entrance according to the capturing ability of prototype B. This changed the final prototype entrance from $5 \mathrm{~cm}$ to 7 $\mathrm{cm}$. A curved wall system was added to the entrance channel, leading to an escape rate of $0 \%$ (Figure 2C). Upon testing the performance of this new concept, we observed an increase in capture rate (Table 2), although this result did not significantly differ from those found using prototype $\mathrm{B}$.
Using the results from this study, we developed an experimental prototype trap referred to as StegTrap that is specifically designed to capture gravid Aedes (Stegomyia) aegypti females. The prototype uses polymethly methacrylate (as its rigid parts) and has a red latex coating. This invention is made up of 1) a body built in the shape of a truncated pyramid with a square base, 2) an entrance for mosquitoes with a zipper to prevent mosquitoes from escaping at the time of trap removal and subsequent transport, 3) two trays that form an upper and a lower compartment, 4) a vertical wall with slots that act as a false exit, 5) a reservoir of the bait that attracts the gravid females, and 6) a red elastic cover (Figure 3). The elastic cover, whose patent has been applied for Parra, et al. $(2014)^{26}$, is used only when the trap is installed in the field.

StegTrap is highly effective in capturing Ae. aegypti mosquitoes, with a capture rate under laboratory conditions of $90.5 \%$. Thus, we took an interdisciplinary approach between industrial design and entomology to develop a trap that addresses the capture of mosquitoes that transmit vector-borne diseases. This approach resulted in a product designed for simple assembly, cleaning, sample extraction and field and laboratory safety $^{27}$.

\section{CONFLICT OF INTEREST}

This study no has conflict of interest

\section{ACKNOWLEDGMENTS}

This study was conducted thanks to the research support program of the "Vicerrectoría de Investigación of the Universidad Industrial de Santander" for Project 5696.

\section{REFERENCES}

1. WHO [World Health Organization]. Vector surveillance and control. In: Dengue hemorrhagic fever: diagnosis, treatment, prevention and control Geneva, Switzerland: World Health Organization. 1997; p 48-59.

2. Morrison AC, Astete H, Chapilliquen E, RamirezPrada G, Diaz G, Getis A, et al. Evaluation of a sampling methodology for rapid assessment of Aedes aegypti infestation levels in Iquitos, Peru. J Med Entomol. 2004; 41(3): 502-510.

3. Kröckel U, Rose A, Eiras AE, Geier M. New tools for surveillance of adult yellow fever mosquitoes: comparison of trap catches with human landing 
rates in an urban environment. J Am Mosq Control Assoc. 2006; 22(2): 229-238.

4. Facchinelli L, Koenraadt CJ, Fanello C, Kijchalao U, Valerio L, Jones JW, et al. Evaluation of a sticky trap for collecting Aedes (Stegomyia) adults in a dengue-endemic area in Thailand. Am J Trop Med Hyg. 2008; 78(6): 904-909.

5. Donalísio MR, Glasser CM. Vigilância entomológica e controle de vetores do dengue. Rev Bras Epidemiol. 2002; 5(3): 259-272.

6. Maciel-de-Freitas R, Eiras AE, Lourenço-deOliveira R. Field evaluation of effectiveness of the BG-Sentinel, a new trap for capturing adult Aedes aegypti (Diptera: Culicidae). Mem Inst Oswaldo Cruz. 2006; 101(3): 321-325.

7. Donatti JE, Gomes AC. Adultrap: descrição de armadilha para adulto de Aedes aegypti (Diptera, Culicidae). Rev Bras Entomol. 2007; 51(2): 255-256.

8. Gama RA, Silva EM, Silva IM, Resende M, Eiras AE. Evaluation of the sticky MosquiTRAP for detecting Aedes (Stegomyia) aegypti (L.) (Diptera: Culicidae) during the dry season in Belo Horizonte, Minas Gerais, Brazil. Neotrop Entomol. 2007; 36(2): 294-302.

9. Chadee DV, Ritchie SA. Oviposition behavior and parity rates of Aedes aegypti collected in sticky traps in Trinidad, West Indies. Acta Trop. 2010; 116(3): 212-216. DOI: 10.1016/j.actatropica.2010.08.008.

10. Ball ST, Ritchie SR. Sampling biases of the BGSentinel trap with respect to physiology, age, and body size of adult Aedes aegypti (Diptera: Culicidae). J Med Entomol. 2010; 47(4): 649-656.

11. Vilela AOP, Figueredo LB, dos Santos JR, Eiras AE, Bonjardim CA, Ferreira PCP, et al. Dengue Virus 3 Genotype I in Aedes aegypti mosquitoes and eggs, Brazil, 2005-2006. Emerg Infect Dis. 2010; 16(6): 989-992. DOI: 10.3201/eid1606.091000.

12. Bernath B, Horváth G, Meyer-Rochow VB. Polarotaxis in egg- laying yellow fever mosquitoes Aedes (Stegomyia) aegypti is masked due to info chemicals. J Insect Physiol. 2012; 58(7): 10001006. DOI: 10.1016/j.jinsphys.2012.05.004.

13. Allan SA, Day JF, Edman JD. Visual ecology of biting flies. Annu Rev Entomol. 1987; 32: 297-316.

14. Land MF, Gibson G, Horwood J, Zeil J. Fundamental differences in the optical structure of the eyes of nocturnal and diurnal mosquitoes. J Comp Physiol A. 1999; 185(1): 91-103.

15. Bentley MD, Day FJ. Chemical ecology and behavioral aspects of mosquito oviposition. Annu Rev Entomol. 1989; 34: 401-421.

16. Sippel WL, Brown AW. Studies of the responses of the female Aedes mosquito. Part V. The role of visual factors. Bull Entomol Research. 1953; 43(4): 567-574. DOI: 10.1017/S0007485300026651.

17. Beckel WE. Oviposition site preference of Aedes mosquitoes (Culicidae) in the laboratory. Mosquito News. 1955; 15: 224-228.

18. Hawley WA. The biology of Aedes albopictus. J Am Mosq Control Assoc. 1988; 4(Suppl 1): 1-39.

19. Hoel DF, Obenauer PJ, Clark M, Smith R, Hughes TH, Larson RT, et al. Efficacy of ovitrap colors and patterns for attracting Aedes albopictus at suburban field sites in north-central Florida. J Am Mosq Control Assoc. 2011; 27(3): 245-251.

20. Muir LE, Thorne JM, Kay BH. Aedes aegypti (Diptera: Culicidae) vision: spectral sensitivity and other perceptual parameters of the female eye. J Med Entomol. 1992; 29(2): 278-281.

21. Muir LE, Kay BH, Thorne JM. Aedes aegypti (Diptera: Culicidae) vision: response stimuli from the optical environmental. J Med Entomol. 1992; 29(3): 445-450.

22. Pei E, Campbell RI, Evans MA. A Taxonomic classification of visual design representations used by industrial designers and engineering designers. Design J. 2009; 14(1): 64-91. DOI: 10.2752/175630 610X12877385838803.

23. Navarro-Silva MA, Marques FA, Duque JEL. Review of semiochemicals that mediate the oviposition of mosquitoes: a possible sustainable tool for the control and monitoring of Culicidae. Rev Bras Entomol. 2009; 53(1): 1-6.

24. Yap HH. Preliminary report on the color preference for oviposition by Aedes albopictus (Skuse) in the field. Southeast Asian J Trop Med Public Health. 1975; 6: 451-453.

25. Yap HH, Lee CY, Chong NL, Foo AES, Lim MP. Oviposition site preference of Aedes albopictus in the laboratory. J Am Mosq Control Assoc. 1995; 11: 128-132.

26. Parra HJ; Duque JEL, Torres JP, Navarro AM. Trampa para captura y monitoreo de Aedes aegypti. Organización Mundial de la Propiedad Intelectual. 2014; WIPO-PCT. WO2014/167553A2

27. Driver AJ, Peralta C, Moultrie J. Exploring how industrial designers can contribute to scientific research. Int J Design. 2011; 5(1): 17-28. 